\title{
BMJ Open Conflict of interest disclosure slides at the European Society of Cardiology Congress 2016 in Rome: are they displayed long enough to assess their content? A cross-sectional study
}

\author{
Christianne T van Lieshout, ${ }^{1}$ Joeri K Tijdink, ${ }^{2}$ Yvo M Smulders ${ }^{1}$
}

To cite: van Lieshout CT, Tijdink JK, Smulders YM. Conflict of interest disclosure slides at the European Society of Cardiology Congress 2016 in Rome: are they displayed long enough to assess their content? A crosssectional study. BMJ Open 2018;8:e023534. doi:10.1136/ bmjopen-2018-023534

- Prepublication history and additional material for this paper are available online. To view these files, please visit the journal online (http://dx.doi org/10.1136/bmjopen-2018023534).

Received 10 April 2018

Revised 4 June 2018

Accepted 12 September 2018

Check for updates

(c) Author(s) (or their employer(s)) 2018. Re-use permitted under CC BY-NC. No commercial re-use. See rights and permissions. Published by BMJ.

${ }^{1}$ Department of Internal Medicine, VU University Medical Center, Amsterdam, The Netherlands

${ }^{2}$ Department of Philosophy, VU University, Amsterdam, The Netherlands

Correspondence to Dr Yvo M Smulders; y.smulders@vumc.nl

\section{ABSTRACT}

Objectives To assess the duration of display of conflict of interest (COI) disclosure slides of presentations at the European Society of Cardiology (ESC) Congress 2016, and to identify factors associated with the duration of display of the disclosure slide.

Design Cross-sectional observational study.

Outcome measures Display duration of the COI disclosure slide and display duration per disclosure. Results Analysis of official video recordings of all oral presentations, viewed on the ESC website. 1673 oral presentations were analysed. In 706 presentations $(42.2 \%)$, COls were present on the disclosure slide. The median display duration of the disclosure slide was $2.49 \mathrm{~s}$ (minimum value: $0.16 \mathrm{~s}$; IQR 1.47-4.08). In multivariable analysis, time spent on COI disclosures was positively related to the number of COls $(+0.11 \mathrm{~s}$ per extra $\mathrm{COI})$, older estimated age of the speaker (+3.92s for 75-85 years compared with $<25$ years), verbally commenting on disclosures (up to $+8.25 \mathrm{~s}$ ) and disclosures being of a non-commercial nature (+2.83s). In addition, speakers from Eastern, Southern and Western Europe, Africa+East Asia and Asia showed their disclosures significantly shorter than the reference group (Northern Europe).

Conclusion $\mathrm{COI}$ disclosure slides are often displayed too briefly to reasonably assess their content. Several factors appear to influence the duration of display of the COI disclosure slides, but none do so to the degree that the display duration becomes sufficiently long.

\section{INTRODUCTION}

Over the past decades, there has been increased attention for the relationship between biomedical research and industry. Research itself as well as individual researchers receive substantial financial support from pharmaceutical companies. ${ }^{1}$ Conflicts of interest (COIs) in scientific publications or at congresses remain under-reported and are often described in unclear or inconsistent ways. ${ }^{2-4}$ There is widespread concern that COIs influence the outcomes of clinical studies. Industry-sponsored studies are
Strengths and limitations of this study

- One of the first studies addressing this topic.

- Large sample size.

- Many possible associations were analysed.

- Duration of display of the conflict of interest disclosure slide could be precisely determined by using video recordings of the presentations.

- Presentations of only one medical congress were analysed.

more likely to report positive results. ${ }^{56} \mathrm{COIs}$ can harm the credibility of research results and therefore may influence the audience's opinion regarding the objectivity of the study. $^{7}$

One way to address COIs arising from financial ties between $\operatorname{research}(\mathrm{ers})$ and industry is to promote transparency. Medical congress organisers intend to promote transparency by mandating the display of COI slides during oral presentations. To actually achieve transparency, however, such slides need to be displayed long enough for the audience to adequately take note of their content. Although the impression that COI slides are often displayed too briefly appears widespread, no large studies have addressed this topic. We therefore decided to analyse the display duration of the COI disclosure slides of all presentations held at the annual meeting of the European Society of Cardiology (ESC) in 2016, one of the largest (33 000 attendants) international medical congresses.

\section{MATERIALS AND METHODS}

Using the ESC website (www.escardio.org), we studied video recordings of all oral presentations held at the ESC Congress 2016 in Rome, 


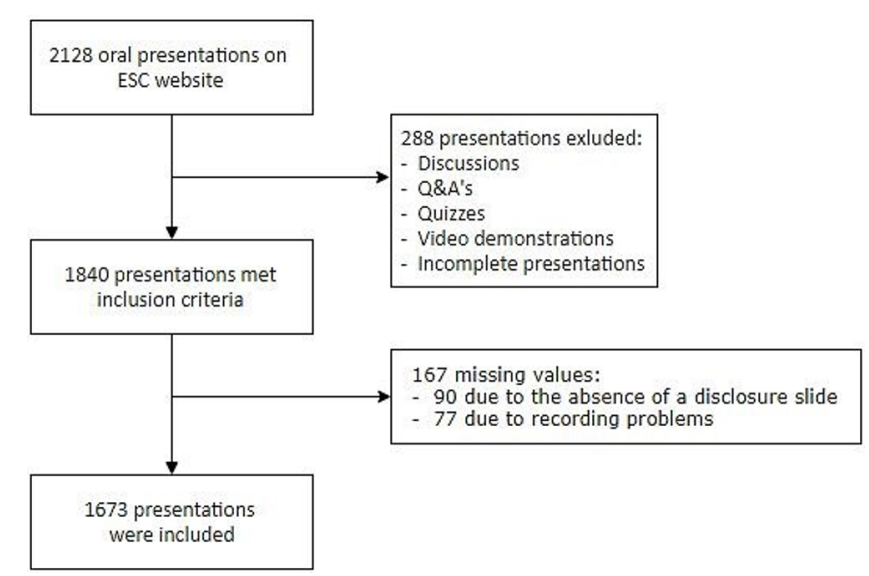

Figure 1 Flowchart of study inclusion. ESC, European Society of Cardiology.

Italy. The ESC Congress regulations state that speakers must declare possible COIs regarding their current presentation on their first slide..$^{8}$ The regulations make no reference to the desired duration of display of this disclosure slide. We excluded video recordings of discussions (panel discussions, discussions with the audience), Q\&A sessions, quizzes, video demonstrations and incomplete presentations (eg, session introductions, session conclusions).

The main outcome was the duration of display of the COI disclosure slide. This duration of display was recorded using a handheld digital stopwatch. All display durations were measured twice, or three times if the two measurements varied by more than $0.20 \mathrm{~s}$. The mean of registered durations was noted. For COI slides containing at least one disclosure, the duration of display of the disclosures was also expressed in display duration per disclosure.

Potential associations of the duration of display of the disclosures were discussed in the project group. Based on consensus regarding plausible relevant factors (the literature contains no data in this respect), the following additional information was obtained from the video recordings: the speaker's gender, estimated age (in decades) and country of location of the speaker's institution; number

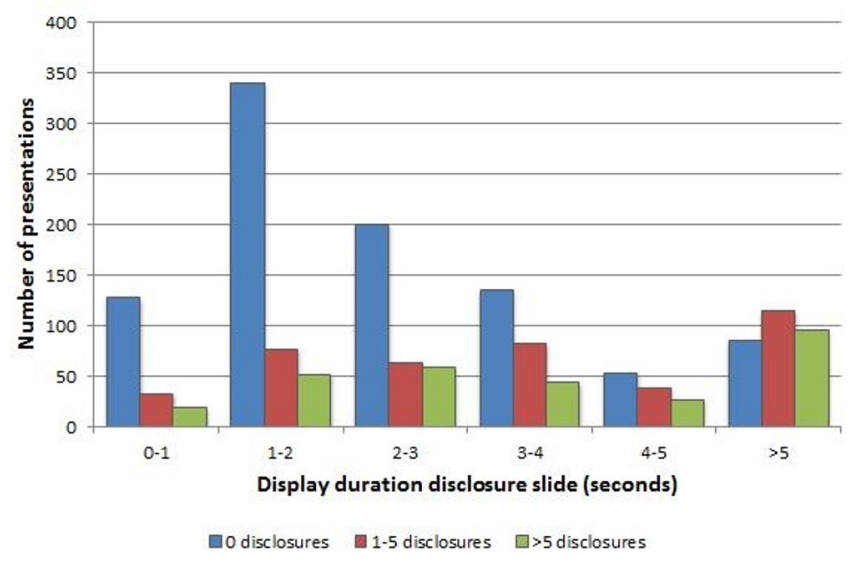

Figure 2 Duration of display of the conflict of interest disclosure slide in relation to the number of disclosures. of COIs presented on the disclosure slide; total duration of the presentation; the subject of the presentation (ie, guideline, experimental study; commercial or non-commercial relevance); if disclosures were presented on the title slide as well as on the COI disclosure slide; if and how COIs were verbally expressed during display of the slide; and nature of COIs (commercial or non-commercial; personal, consultancy or research funding). Commercial COIs are pharmaceutical or device companies; non-commercial disclosures are government funding or public funding. Countries of location of the speaker's institution were clustered following the geographic regions of the United Nations. ${ }^{9}$

\section{Statistical analysis}

Routine bivariate tests were used, as appropriate. Multiple linear regression was used to identify independent associations of duration of display of the COI disclosure slide. Statistical analysis was performed using Statistical Package for Social Sciences V.23.0 (IBM Corporation, Armonk, New York, USA).

\section{Patient and public involvement}

There were no patients involved in this study. The results will be disseminated to relevant individuals (eg, speakers during ESC congresses) and general scientific audience via this publication, as well as communication to the ESC itself.

\section{RESULTS}

\section{Presentation characteristics and overall duration of display of the disclosures}

The website contained 2128 video recordings of oral presentations. Although it was an ESC congress stipulation, in $4.9 \%$ of the presentations meeting the inclusion criteria, a disclosure slide was absent $(\mathrm{n}=90)$. After selection, 1673 presentations were eligible for inclusion (see figure 1 for flowchart). One or more disclosures were declared in 724 presentations (43.3\%); 948 disclosure slides $(56.7 \%)$ contained no disclosures. Among the presentations with disclosures, the median number of disclosures was 5 (range 1 to 41 ).

Overall, median duration of display of the COI disclosure slide was $2.49 \mathrm{~s}$ (IQR 1.47-4.08), and time spent per disclosure was $0.78 \mathrm{~s}$ (IQR 0.32-1.94) (see online supplementary table ST1). The fastest duration of display of the COI slide was $0.16 \mathrm{~s}$.

\section{Factors associated with the disclosure time: univariate analyses}

The number of COIs to disclose showed a moderate positive association with the display duration of the COI slide (Spearman's correlation coefficient $\mathrm{r}=0.312 ; \mathrm{p}<0.001$ ), and a strong negative association with the duration of display per disclosure $(\mathrm{r}=-0.714, \mathrm{p}<0.001)$. The total duration of the presentations (median $16.03 \mathrm{~min}$, range 1.00 to $38.27 \mathrm{~min}$ ) was not related to the COI display 
Table 1 Presentation characteristics and univariate analyses of associations with disclosure time

\section{COI display duration}

\section{Characteristics}

N Median IQR

Gender

Male

Female

Estimated age $\dagger$

\begin{tabular}{rrrrrrrrrrrl}
$15-25$ & 5 & 1.98 & 1.48 & 6.71 & 0.000 & 1 & - & - & - & 0.000 \\
\hline $25-35$ & 213 & 2.38 & 1.52 & 3.45 & & 37 & 2.34 & 0.95 & 4.44 & \\
$35-45$ & 325 & 2.56 & 1.48 & 6.59 & & 92 & 1.02 & 0.30 & 2.31 \\
$45-55$ & 367 & 2.46 & 1.31 & 4.24 & & 158 & 0.70 & 0.32 & 2.41 \\
$55-65$ & 619 & 2.51 & 1.52 & 4.29 & & 331 & 0.69 & 0.30 & 1.51 \\
$65-75$ & 129 & 2.96 & 1.67 & 6.30 & & 78 & 0.69 & 0.27 & 1.66 \\
$75-85$ & 14 & 5.00 & 1.42 & 16.64 & & 9 & 1.02 & 0.65 & 2.67
\end{tabular}

Region of location of the speaker's institution

\begin{tabular}{|c|c|c|c|c|c|c|c|c|c|c|}
\hline Northern Europe & 294 & 3.06 & 1.68 & 4.92 & 0.000 & 138 & 1.20 & 0.63 & 3.16 & 0.000 \\
\hline Eastern Europe & 74 & 2.04 & 1.26 & 3.27 & & 27 & 0.55 & 0.14 & 0.99 & \\
\hline Southern Europe & 356 & 1.89 & 1.27 & 3.37 & & 101 & 0.58 & 0.26 & 1.32 & \\
\hline Western Europe & 544 & 2.59 & 1.53 & 4.18 & & 269 & 0.62 & 0.28 & 1.63 & \\
\hline USA+Canada & 208 & 3.43 & 1.91 & 6.27 & & 136 & 0.86 & 0.38 & 2.71 & \\
\hline Central+South America & 19 & 2.49 & 1.58 & 3.81 & & 4 & 2.52 & 0.70 & 3.07 & \\
\hline Africa+East Asia & 36 & 1.62 & 0.92 & 2.54 & & 5 & 0.98 & 0.16 & 4.76 & \\
\hline Asia & 119 & 2.35 & 1.52 & 3.45 & & 18 & 1.37 & 0.41 & 2.34 & \\
\hline Australia+New Zealand & 23 & 2.33 & 1.17 & 2.77 & & 8 & 0.57 & 0.32 & 5.57 & \\
\hline \multicolumn{11}{|l|}{ Subject type $†$} \\
\hline Guideline & 90 & 2.07 & 1.28 & 3.31 & 0.039 & 46 & 0.38 & 0.17 & 1.50 & 0.000 \\
\hline Overview & 576 & 2.66 & 1.48 & 4.48 & & 323 & 0.65 & 0.29 & 1.50 & \\
\hline Observational study & 390 & 2.65 & 1.61 & 3.85 & & 102 & 1.73 & 0.60 & 4.11 & \\
\hline Experimental study & 161 & 2.85 & 1.87 & 4.01 & & 70 & 0.91 & 0.38 & 2.55 & \\
\hline Case report & 179 & 2.13 & 1.35 & 3.36 & & 61 & 0.77 & 0.29 & 1.39 & \\
\hline Informative talk & 255 & 2.19 & 1.29 & 4.49 & & 102 & 0.85 & 0.33 & 1.93 & \\
\hline Systematic review & 21 & 3.71 & 2.16 & 4.85 & & 2 & 3.86 & 2.12 & - & \\
\hline \multicolumn{11}{|l|}{ Subject of presentation $\ddagger$} \\
\hline Commercial relevance & 425 & 3.26 & 1.97 & 5.09 & 0.000 & 281 & 0.72 & 0.33 & 4.82 & 0.831 \\
\hline No commercial relevance & 1246 & 2.26 & 1.36 & 3.78 & & 425 & 0.79 & 0.30 & 1.92 & \\
\hline \multicolumn{11}{|c|}{ Disclosures also presented on title slide } \\
\hline No & 1618 & 2.54 & 1.49 & 4.15 & 0.000 & 687 & 0.79 & 0.32 & 1.96 & 0.031 \\
\hline Yes & 55 & 1.64 & 1.01 & 2.30 & & 19 & 0.42 & 0.26 & 0.88 & \\
\hline \multicolumn{11}{|l|}{ Disclosures present $†$} \\
\hline Absent & 948 & 2.00 & 1.27 & 3.20 & 0.000 & - & - & - & - & - \\
\hline Present (median \# is 5) & 724 & 3.44 & 2.00 & 6.27 & & 706 & 0.78 & 0.32 & 1.94 & \\
\hline \multicolumn{11}{|l|}{ Verbal disclosure§ } \\
\hline No & 536 & 1.31 & 0.93 & 1.86 & 0.000 & 175 & 0.39 & 0.22 & 0.97 & 0.000 \\
\hline Yes, 'present' & 1000 & 2.99 & 2.06 & 4.51 & & 407 & 0.72 & 0.33 & 1.65 & \\
\hline Yes, partially specified & 102 & 11.11 & 6.58 & 15.54 & & 90 & 1.75 & 0.81 & 4.10 & \\
\hline Yes, complete & 35 & 7.84 & 5.31 & 11.30 & & 34 & 6.33 & 4.10 & 9.02 & \\
\hline
\end{tabular}

Continued

Duration per disclosure

Sig* N Median IQR

Sig $^{*}$

$\begin{array}{llll}1322 & 2.60 & 1.52 & 4.29\end{array}$

4.29

0.000

$622 \quad 0.72$

0.30

1.76

0.000

$\begin{array}{llll}84 & 1.31 & 0.51 & 6.92\end{array}$

\section{政}

กิ

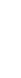


Table 1 Continued

\begin{tabular}{|c|c|c|c|c|c|c|c|c|c|c|}
\hline \multirow[b]{2}{*}{ Characteristics } & \multicolumn{5}{|c|}{ COI display duration } & \multicolumn{4}{|c|}{ Duration per disclosure } & \multirow[b]{2}{*}{ Sig $^{*}$} \\
\hline & $\mathbf{N}$ & Median & IQR & & Sig $^{*}$ & $\mathbf{N}$ & Median & IQR & & \\
\hline Commercial COI & 599 & 3.24 & 1.93 & 5.41 & 0.000 & 594 & 0.79 & 0.33 & 1.97 & 0.000 \\
\hline Non-commercial COI & 29 & 4.80 & 2.63 & 14.34 & & 29 & 3.67 & 1.85 & 10.26 & \\
\hline Both & 86 & 4.57 & 2.26 & 8.71 & & 79 & 0.42 & 0.19 & 0.92 & \\
\hline \multicolumn{11}{|l|}{ Type of $\mathrm{COl}^{\star *}$} \\
\hline Personal & 111 & 3.07 & 2.02 & 5.31 & 0.600 & 107 & 1.65 & 0.44 & 3.13 & 0.000 \\
\hline Consultancy & 108 & 3.21 & 1.85 & 4.88 & & 108 & 1.23 & 0.61 & 3.21 & \\
\hline Research & 120 & 3.64 & 2.11 & 7.15 & & 114 & 1.57 & 0.82 & 3.42 & \\
\hline Any combination & 378 & 3.51 & 1.96 & 5.27 & & 367 & 0.49 & 0.25 & 0.99 & \\
\hline
\end{tabular}

*Significance level is the $\mathrm{p}$ value of the logarithmically transformed COI display duration.

†One missing value.

‡Two missing values.

§Presence of verbal disclosure is subdivided in no verbal disclosure; solely mentioning the presence or absence of disclosures; a partial specification of the disclosed COI (eg, 'research funding'); or a complete verbal disclosure (eg, including pharmaceutical company names). ПCommercial COls are that with pharmaceutical or device companies; non-commercial disclosures are that with government funding or public funding.

**Personal disclosures are eg, lecture fees and travel support, consultancy disclosures include royalties, ownership and stockholdership. $\mathrm{COI}$, conflict of interest.

duration $(\mathrm{r}=0.009, \mathrm{p}=0.352)$. Even among presentations with extremely short $(0-1 \mathrm{~s})$ or very short (1-2s) duration of display of the COI slide, a significant number of speakers had multiple COIs (figure 2). COI duration of display was slower for presentations with at least one disclosure (median 3.44s) compared with no disclosures (median 2.00s).

Univariate analyses of potential factors associated with the disclosure duration are further explored in table 1. Men had a longer duration of display of the COI disclosure slide, with a median difference of $0.40 \mathrm{~s}$ and there was a positive association between estimated age and disclosure duration. If the disclosed COI were commercial, median
COI duration of display was $3.24 \mathrm{~s}$, compared with $4.80 \mathrm{~s}$ for non-commercial disclosures.

COI display duration differed between geographic regions. The median duration of display of the different regions is shown in figure 3 . For individual countries with $n>30$ presentations, the median duration of display of the COI slide and duration per disclosure are shown in online supplementary figure S1 (web appendix): speakers from the USA display their disclosures longer (median 3.46s) than all other countries; Great Britain is second best (median 3.23s). The median COI duration of display and median time per disclosure for all individual countries (including those with

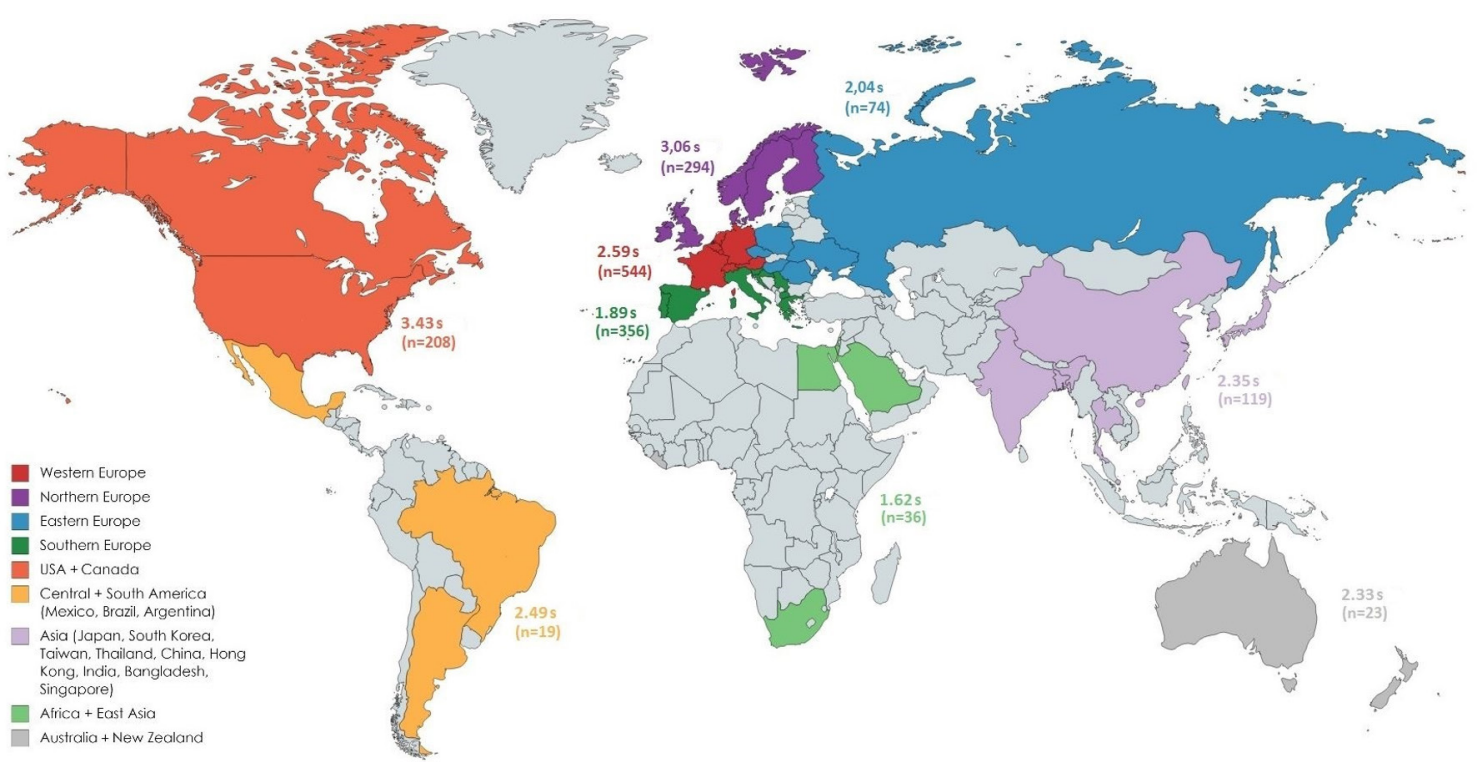

Figure 3 Regions of location of the speaker's institution, based on the United Nations geographic regions. ${ }^{9}$ 


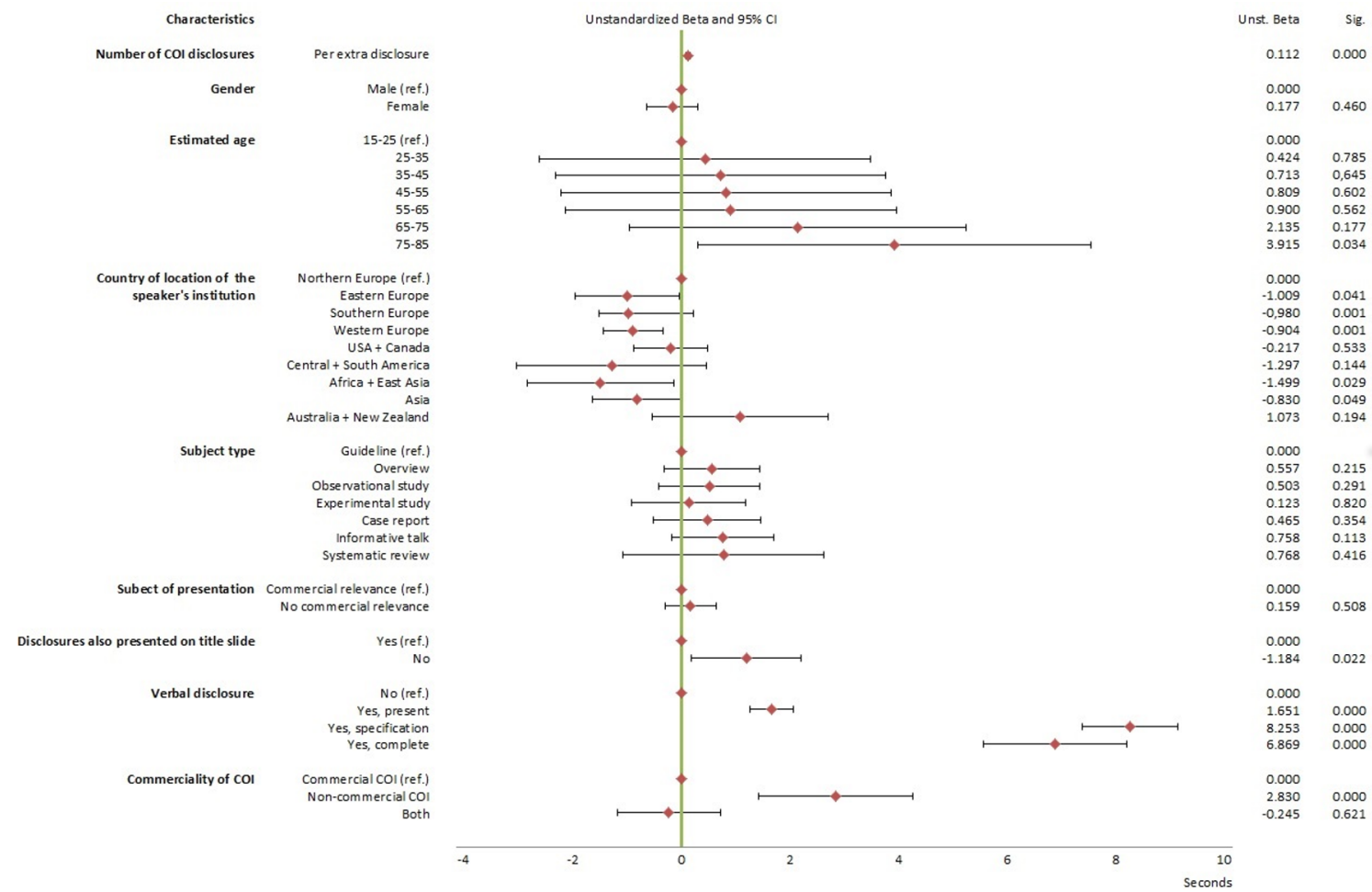

Figure 4 Forest plot of the multiple linear regression with disclosure time as dependent variable. COI, conflict of interest.

$\mathrm{n} \leq 30$ presentations) are shown in online supplementary table ST1.

\section{Multivariate analysis}

Variables that were significantly associated with total duration of display of the COI disclosure slide in univariate analyses (table 1) were entered in a multiple linear regression model, the results of which were largely congruent to the univariate analyses (figure 4). The independent contribution of the number of COIs to disclose is clearly limited, to just $0.11 \mathrm{~s}$ per extra COI. A significantly longer COI duration of display was seen in the highest age group (75-85 years: $+3.92 \mathrm{~s}$ compared with the youngest age group), in speakers verbalising the disclosures (up to $+8.25 \mathrm{~s}$ ) and having non-commercial disclosures $(+2.83 \mathrm{~s})$. Apart from these factors, speakers from Eastern, Southern and Western Europe, Africa+East Asia and Asia displayed their disclosures significantly shorter than the reference group (Northern Europe).

\section{DISCUSSION}

This study using data from one of the largest existing annual medical congresses reveals a median duration of display of the disclosure slide of just $2.49 \mathrm{~s}$. An increase in number of disclosures prolongs the duration of display only by $0.11 \mathrm{~s}$ per extra disclosure. A verbal comment on the disclosures prolongs the COI duration of display as well. Interestingly, the duration of display is longer when disclosures are non-commercial, compared with commercial disclosures. Finally, estimated age of the speaker and country of location of the speaker's institution are factors independently associated with the duration of display of the disclosure slide. Taken together, our results indicate that disclosure slides are often displayed too briefly to adequately assess its content, leaving room for improvement. Several factors appear to influence the duration of display of the COI disclosure slides; however, none of those factors do so to the degree that the display duration becomes sufficiently long.

The pharmaceutical industry is a large funder of research and its commercial involvement may affect the design and results of clinical trials, generally favouring interests of the sponsor. ${ }^{5}$ The essential purpose of COI disclosure policies is the preservation of trust in science and among scientists. ${ }^{10}$ COI policies oblige speakers to display a disclosure slide to provide listeners' insight in COIs that possibly influence their research results.

To our knowledge, four substantially smaller previous studies addressed this topic. An analysis of 86 scientific presentations at the 2010 Annual Scientific Meeting of the American Urogynaecologic Society found a mean display time of the disclosure slide of $4.2 \mathrm{~s}^{2}{ }^{2}$ In 2012, 139 presentations at the congress of the American Academy of Orthopaedic Surgeons were analysed with an average display duration of $3.1 \mathrm{~s}$. In this study $86 \%$ of the speakers spoke about their disclosures, compared with $68 \%$ in our study. ${ }^{11}$ In 2016, an analysis of 469 presentations at the American Society of Clinical Oncology meetings in 2014 and 2015 showed that the duration of the COI slightly decreased from 6 to $5 \mathrm{~s}^{12}$ Another study of 201 oral presentations at five medical congresses in 2016 found a median display duration of the COI slide of $2 \mathrm{~s} .{ }^{13}$ They also found 
that the total duration of the presentation was not associated with the duration of display of the COI disclosure slide, which is consistent with our findings. The results of these previous studies suggest that the short duration of display of the disclosure slide is not limited to the cardiology field, but occurs in other fields of medicine as well.

Strengths of this study include the large sample size, the possibility of precisely registering the duration of display of the COI slide by making use of video recordings and the inclusion of many potential factors associated with the display duration of the disclosure slide in the database. Limitations are that the age of the speakers had to be estimated and that we did not distinguish preclinical/ laboratory work from clinical studies. Furthermore, we analysed just one, although very large, medical congress. This makes it difficult to extrapolate our results to other fields than cardiology.

In conclusion, our results suggest that more attention should be paid to appropriate disclosure of COIs during medical congresses. Mandatory verbalisation of COIs or a minimum display duration of the disclosure slide should be considered.

Contributors YMS conceived the idea of the study. CTVL conducted the analyses with the supervision of JKT and YMS. All authors contributed to the analyses, content and critical revisions to the drafts of the paper. All authors gave final approval of the version to be published and agreed to be accountable for all aspects of the work.

Funding The authors have not declared a specific grant for this research from any funding agency in the public, commercial or not-for-profit sectors.

Competing interests None declared.

Patient consent Not required.

Provenance and peer review Not commissioned; externally peer reviewed.

Data sharing statement No additional data are available.
Open access This is an open access article distributed in accordance with the Creative Commons Attribution Non Commercial (CC BY-NC 4.0) license, which permits others to distribute, remix, adapt, build upon this work non-commercially, and license their derivative works on different terms, provided the original work is properly cited, appropriate credit is given, any changes made indicated, and the use is non-commercial. See: http://creativecommons.org/licenses/by-nc/4.0/.

\section{REFERENCES}

1. Rose SL, Krzyzanowska MK, Joffe S. Relationships between authorship contributions and authors' industry financial ties among oncology clinical trials. J Clin Oncol 2010;28:1316-21.

2. Ramm O, Brubaker L. Conflicts-of-interest disclosures at the 2010 AUGS Scientific Meeting. Female Pelvic Med Reconstr Surg 2012;18:79-81.

3. Dunn AG, Coiera E, Mandl KD, et al. Conflict of interest disclosure in biomedical research: a review of current practices, biases, and the role of public registries in improving transparency. Res Integr Peer Rev 2016;1.

4. Okike K, Kocher MS, Wei EX, et al. Accuracy of conflict-of-interest disclosures reported by physicians. N Engl J Med 2009;361:1466-74.

5. Bekelman JE, Li Y, Gross CP. Scope and impact of financial conflicts of interest in biomedical research: a systematic review. JAMA 2003;289:454-65.

6. Lundh A, Sismondo S, Lexchin J, et al. Industry sponsorship and research outcome. Cochrane Database Syst Rev 2012;12:MR000033.

7. Kesselheim AS, Robertson CT, Myers JA, et al. A randomized study of how physicians interpret research funding disclosures. $N$ Engl $J$ Med 2012;367:1119-27.

8. ESC European Society of Cardiology. Regulations for invited speakers and chairpersons. https://www.escardio.org/Congresses-\&Events/ESC-Congress/Scientific-sessions/Regulations-for-invitedspeakers-and-chairpersons (Retrieved on 24 May 2018).

9. Statistics Division of the United Nations Secretariat. Standard country or area codes for statistical use (M49). https://unstats.un.org/ unsd/methodology/m49/ (Accessed 30 Nov 2017).

10. Fineberg HV. Conflict of interest: why does it matter? JAMA 2017;317:1717-8.

11. Sassoon AA, Trousdale RT. Podium disclosures at the 2012 AAOS meeting: an exercise in going through the motions. $J$ Bone Joint Surg Am 2013;95:e51.

12. Boothby A, Wang R, Cetnar J, et al. Effect of the American Society of clinical oncology's conflict of interest policy on information overload. JAMA Oncol 2016;2:1653-4.

13. Grey A, Avenell A, Dalbeth N, et al. Reporting of conflicts of interest in oral presentations at medical conferences: a delegate-based prospective observational study. BMJ Open 2017;7:e017019. 